\title{
Brief
}

\section{Supine position with alternating inflation pneumatic cuffs in video- assisted thoracoscopic surgery for bilateral pneumothorax}

\author{
Pei-Ming Huang, MD, Yih-Leong Chang, MD, Hsao-Hsun Hsu, MD, Jin-Shing Chen, MD, Jang-Ming Lee, MD, PhD, and
} Yung-Chie Lee, MD, PhD, Taipei, Taiwan

\footnotetext{
From the Department of Surgery, National Taiwan University Hospital, Taipei, Taiwan.

Received for publication March 15, 2004; accepted for publication June 2, 2004.

Address for reprints: Yung-Chie Lee, MD, $\mathrm{PhD}$, Department of Surgery, National Taiwan University Hospital, No. 7, ChungShan S Rd, Taipei 100, Taiwan (E-mail: wuj@ ha.mc.ntu.edu.tw).

J Thorac Cardiovasc Surg 2005;129:437-9 $0022-5223 / \$ 30.00$
}

Copyright (C) 2005 by The American Association for Thoracic Surgery

doi:10.1016/j.jtcvs.2004.06.004
$\mathrm{P}$ rimary spontaneous pneumothorax (SP) has a tendency toward bilateral bullous lesions of the lung, with incidence ranging from $7.8 \%$ to $20 \%$ of the total cases of $\mathrm{SP}$ A previous study demonstrated that bilateral video-assisted thoracoscopic surgery (VATS) in the supine position is feasible in the treatment of bilateral $\mathrm{SP}^{2-4}$ In the past, we have used sequential inflation pneumatic cuffs to simplify these procedures.

\section{Methods and Results}

Nine patients with bilateral simultaneous $(\mathrm{n}=2)$ and nonsimultaneous $(\mathrm{n}=7)$ contralateral primary SP were treated by single-stage bilateral VATS between July 1999 and July 2003. Five patients underwent sequential bilateral VATS in the full lateral decubitus position (conventional group), and the remaining 4 patients underwent bilateral VATS in the supine position with the assistance of two pneumatic cuffs (supine group).

In the conventional group, one $12-\mathrm{mm}$ trocar was inserted through a $1.5-\mathrm{cm}$ skin incision in the eighth intercostal space at the midaxillary line or through the previous chest tube wound for the application of a $30^{\circ}$ videothoracoscope (Karl Storz, Tüttlingen, Germany). Two additional working ports were then approached under direct endoscopic vision. When no blebs were visible, a small portion of the apex of the lung or a visible lesion was resected with an endoscopic stapler (EZ 45; Ethicon Endo-Surgery, Inc, Cincinnati, Ohio). Vigorous abrasion of the entire pleura was performed with a strip of diathermy scratch pad. The patient was then rotated to the opposite lateral decubitus position, and an identical procedure was performed.

In the supine group, the patient's thighs were loosely secured with straps to the operating table to make sure that the patient did not slide off of the table when it was maxillary rotated to its side. However, two sets of independent, inflated 6-inch pneumatic cuffs, which have been commonly used in orthopedic procedures for damping blood flow, were placed simultaneously at the patient's back (Figure 1, A). The operating table was rotated completely to the contralateral side, and the cuff on the ipsilateral side was gradually inflated to $400 \mathrm{~mm} \mathrm{Hg}$. The port site strategy is illustrated in Figure 1, $B$.

Table 1 shows patient demographic data and surgical outcomes in both groups. Statistical analysis was performed with the 2 -tailed $t$ test. The mean operative times for the supine and conventional groups were $126.3 \pm 21.4$ minutes (range 100-150 minutes) and $162 \pm 35.8$ minutes (range 140-225 minutes), respectively, a statistically insignificant difference $(P=$ .12). All patients completed the treatment as planned without any conversions to conventional bilateral VATS.

\section{Discussion}

Several articles have confirmed excellent results with single-stage bilateral VATS for bilateral SP $2-4$ Bilateral VATS may reduce postoperative pain, permitting favorable immediate postoperative pulmonary function and total correction. Traditionally, patients have been placed in the full lateral decubitus position for VATS procedures because bilateral VATS provides limited access to the posterior and basal portions of the lung in the supine position. In our study, however, the inflated pneumatic cuffs allowed the 
A

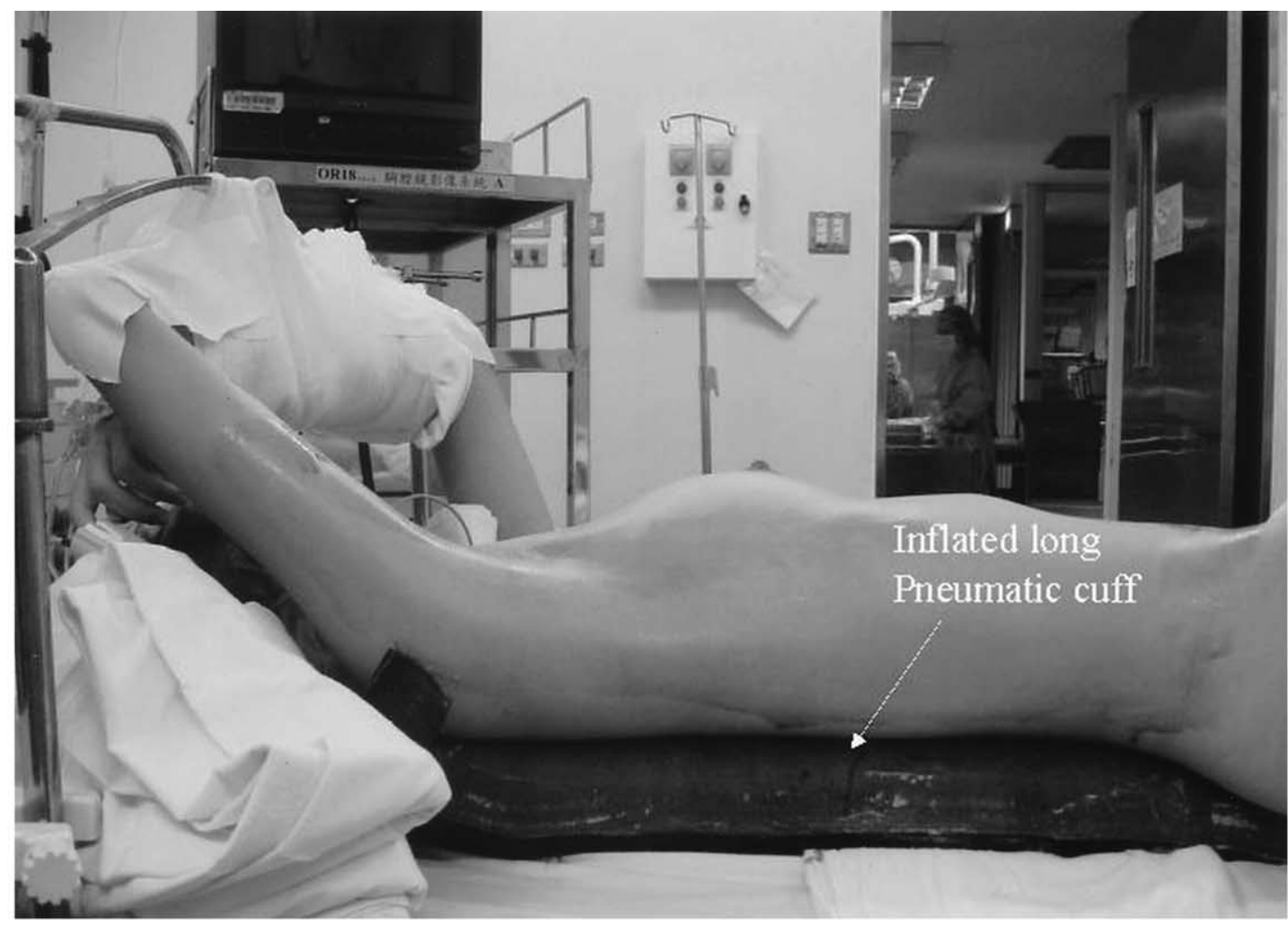



B

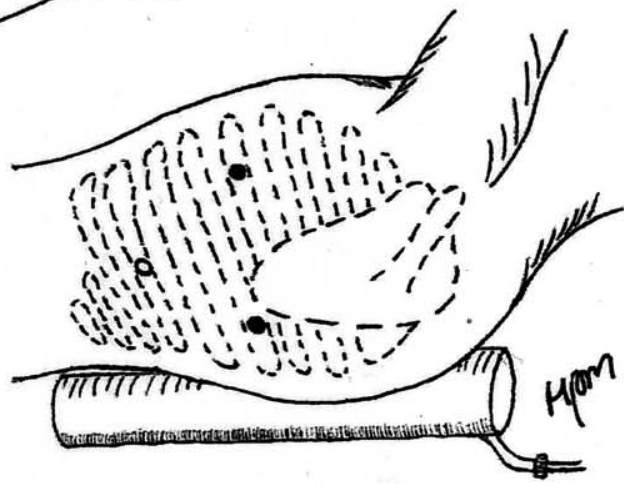

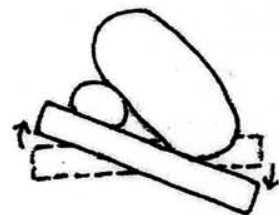

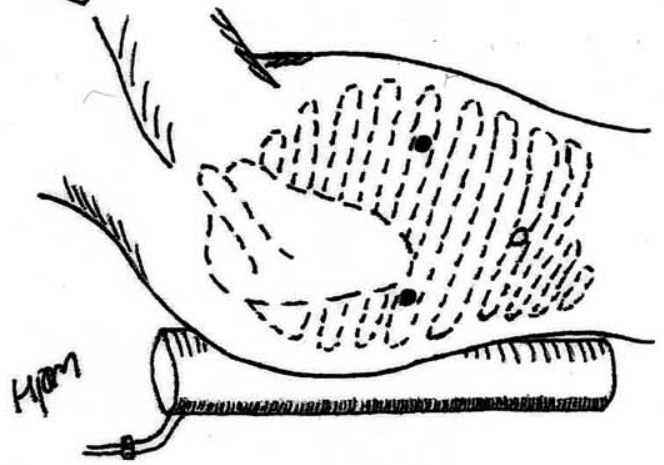

Figure 1. A, Patient was placed in supine position with bilateral long pneumatic cuffs beneath back. Patient's arms were elevated and fixed above face. B, Schema of patient positioning and trocar sites for bilateral VATS. Open circle indicates camera port. Closed circles indicate working ports.

convenience of a clear operative field. Moreover, elevating the back with inflated cuffs has been beneficial for inserting a trocar in the posterior region and made pleurodesis easier. This modified operative technique offered us an excellent alternative to solve difficulties in the manipulation of instruments and de- crease the amount of cumbersome position changes, sterilization, and draping. Importantly, this modification decreased the occurrence of the dislocation of endotracheal tube placement and chest tube kicking during rotation of the patient to the opposite lateral decubitus position. 
TABLE 1. Demographic and perioperative data of 9 patients with bilateral SP treated by sequential bilateral VATS in the full lateral decubitus or supine position with pneumatic cuff assistance

\begin{tabular}{|c|c|c|c|c|c|c|c|c|c|c|}
\hline Patient & Age (y) & Sex & $\begin{array}{l}\text { Operative } \\
\text { indication }\end{array}$ & $\begin{array}{l}\text { Operative } \\
\text { finding }\end{array}$ & $\begin{array}{l}\text { Operative } \\
\text { time (min) }\end{array}$ & $\begin{array}{c}\text { Staples } \\
\text { (R/L) }\end{array}$ & $\begin{array}{c}\text { Pleural } \\
\text { drainage } \\
\text { duration } \\
\text { (d, R/L) }\end{array}$ & $\begin{array}{c}\text { Postoperative } \\
\text { hospital stay } \\
\text { (d) }\end{array}$ & Complications & $\begin{array}{l}\text { Follow-up } \\
\text { (mo) }\end{array}$ \\
\hline \multicolumn{11}{|c|}{ Conventional group } \\
\hline 1 & 15 & $M$ & CSP & $\begin{array}{l}\text { RUL, R B6, } \\
\text { LUL blebs }\end{array}$ & 155 & $2 / 2$ & $10 / 12$ & 14 & $\mathrm{R}$ air leak & 44 \\
\hline 2 & 18 & M & BSP & $\begin{array}{l}\text { RUL, LUL } \\
\text { blebs, L } \\
\text { adhesion }\end{array}$ & 225 & $2 / 3$ & $4 / 3$ & 5 & - & 43 \\
\hline 3 & 19 & $M$ & CSP & $\begin{array}{l}\text { RUL, LUL } \\
\text { blebs }\end{array}$ & 140 & $3 / 3$ & $4 / 3$ & 5 & $\mathrm{R}$ recurrence & 40 \\
\hline 4 & 25 & $M$ & CSP & $\begin{array}{l}\text { R scarring, } \\
\text { LUL blebs }\end{array}$ & 150 & $2 / 2$ & $4 / 6$ & 7 & - & 30 \\
\hline 5 & 16 & $M$ & CSP & $\begin{array}{l}\text { RUL, LUL } \\
\text { blebs }\end{array}$ & 140 & $3 / 3$ & $4 / 3$ & 3 & - & 22 \\
\hline Mean \pm SD & $18.6 \pm 3.9$ & & & & $162 \pm 35.8$ & $2.4 / 2.6$ & $5.2 / 5.4$ & $6.8 \pm 4.3$ & & $35.8 \pm 9.5$ \\
\hline \multicolumn{11}{|l|}{ Supine group } \\
\hline 1 & 20 & M & CSP & $\begin{array}{l}\text { RUL, LUL } \\
\text { blebs }\end{array}$ & 120 & $2 / 2$ & $4 / 5$ & 6 & - & 13 \\
\hline 2 & 16 & $\mathrm{M}$ & BSP & $\begin{array}{l}\text { RUL, R } \\
\text { major } \\
\text { fissure, } \\
\text { LUL blebs }\end{array}$ & 135 & $3 / 2$ & $3 / 5$ & 6 & - & 12 \\
\hline 3 & 35 & $M$ & CSP & $\begin{array}{l}\text { RUL, LUL } \\
\text { blebs, L } \\
\text { adhesion }\end{array}$ & 150 & $2 / 4$ & $4 / 4$ & 5 & - & 11 \\
\hline 4 & 18 & $\mathrm{~F}$ & CSP & $\begin{array}{l}\text { RUL, LUL } \\
\text { blebs }\end{array}$ & 100 & $2 / 1$ & $6 / 6$ & 7 & - & 8 \\
\hline Mean $\pm S D$ & $22.3 \pm 8.7$ & & & & $126.3 \pm 21.4$ & $2.3 / 2.3$ & $4.3 / 5$ & $6 \pm 0.8$ & & $11 \pm 2.2$ \\
\hline$P$ value & .42 & & & & .12 & & & .73 & & .001 \\
\hline
\end{tabular}

$R$, Right; $L$, left; $C S P$, contralateral pneumothorax; $R U L$, right upper lobe; $B 6, \mathrm{~B} 6$ segment of right lower lobe; $L U L$, left upper lobe; $B S P$, bilateral simultaneous pneumothorax.

\section{References}

1. Ikeda M, Uno A, Yamane Y, Hagiwara N. Median sternotomy with bilateral bullous resection for unilateral spontaneous pneumothorax, with special reference to operative indications. J Thorac Cardiovasc Surg. 1998;96,615-20.

2. Lang-Lazdunski L, de Kerangal X, Pons F, Jancovici R. Primary spontaneous pneumothorax: one-stage treatment by bilateral videothoracoscopy. Ann Thorac Surg. 2000;70:412-7.
3. Maruyama R, Anai H. Video-assisted thoracoscopic surgery for bilateral spontaneous pneumothorax in supine position: the use of a pillow beneath the back for intercostal space widening. Thorac Cardiovasc Surg. 2000;48:370-1.

4. Watanabe SI, Nakamura Y, Kariatsumari K, Sakasegawa KI, Mukaihara K, Sakata R. A single-stage video-assisted thoracoscopic surgery procedure for simultaneous bilateral spontaneous pneumothorax in a supine position. Thorac Cardiovasc Surg. 2003;51: 103-5. 